\title{
The Application Research on Chinese Traditional Patterns in the Design of Bamboo and Rattan Furniture
}

\author{
Ruofu Bai \\ Academy of Fine Arts \\ Xuchang University \\ Xuchang, Henan, 461000
}

\begin{abstract}
Bamboo and rattan furniture is made of bamboos and rattans, which has a long history and fresh and elegant style. Its patterns are abundant and changeable and very popular with customers. This paper is aimed at the research of the woven patches and patterns of modern bamboo and rattan furniture and tries to integrate Chinese traditional patterns into the production of modern bamboo and rattan furniture according to the demand on the creative design of bamboo and rattan furniture. Combining Chinese traditional culture with bamboo and rattan furniture to improve the tradition value of bamboo and rattan furniture and give bamboo and rattan furniture new artistic vitality.
\end{abstract}

Keywords-tradition patterns; rattan; rattan furniture; furniture design

\section{INTRODUCTION}

Bamboo and rattan furniture has a long history. It was common as early as 16th century in China and other Asian countries. In the 18th century, bamboo and rattan furniture is spread to Europe and got the favor of western countries with the features of low mass, sturdiness, high earthquake-resistance and cleanability. Until the mid and late 19th century, bamboo and rattan furniture was so popular that it has become the most fashionable outdoor furniture. At that time some western countries in Europe and America produced a large amount of modern bamboo and rattan furniture by combining Asian bamboo and rattan furniture with local culture, which turned this kind of Asian traditional furniture into artwork and developed a huge commercial value.

Bamboo and rattan furniture experienced 100-year's development from the 19th century to 20th century. From 1870 to 1890, the patterns and designs of bamboo and rattan furniture were influenced by western Victoria style and there were much sumptuous decoration on it. For instance, there was some floral pattern decoration and ribbon pattern decoration on part of bamboo and rattan furniture and arch in the whole shape, which made it richer. During that period, bamboo and rattan furniture not only appeared in the houses of ordinary people but also the rich and the nobility. Then the furniture with simple design appeared because of the rise of arts and crafts movement. From 1890 to 1910, people began to change their mind and realized that excessive decoration was flamboyant and stodgy. As a result, lines and geometric patterns appeared on bamboo and rattan furniture whose overall style was simple and decent and design was practical. During 1910 to 1930, new furniture material came out due to the development of technology. Furniture with the combination of leather and cloth became the mainstream in the market at that period. Under that influence, leather and cloth had to be added on the backrest and part of bamboo and rattan furniture. In addition, its material had to be changed into fiber and its processing technology which was by hand originally changed into machinery technology with high efficiency. During that time, its colors were more than before, in which were added white, green and black, etc. After 1930, bamboo and rattan furniture began to decline because of the entering of plastic and metal furniture, the use of poor-quality material and its low production efficiency. It wasn't popular until 1960, when bamboo and rattan furniture became renewed in antique market, found its origin and adopted the eastern Asian style.

The use and development of Chinese bamboo and rattan furniture can be traced back to the ancient. Chinese began to use mats woven by bamboo and rattan as their furniture during daily life for sitting or sleeping before Han Dynasty according to research. After that, its technology had been improved and furniture like rattan beds, rattan chairs and rattan screens came into their life. There still preserved bamboo and rattan furniture in the sunken ship of Zheng He from Ming Dynasty. Ming and Qing Dynasty also had the exquisite bamboo and rattan furniture. Now bamboo and rattan furniture has become our common furniture in our daily life. But there are also some bad aspects. The technology of such furniture is not excellent. Its production is so limited that it can't keep up with the modern trend. Also, it doesn't make full use of Chinese traditional culture. The creation of our local products is lagged behind other countries. In spite of that, bamboo and rattan furniture has a splendid future. Even the world class furniture manufacturers begin to develop the new creative bamboo and rattan furniture after realizing its unique charm. Bamboo and rattan furniture also appeared in the famous international red dot design competition. All those indicate that bamboo and rattan furniture industry still has a great developing space, the 
key of which is how to explore its unique charm and show its unique cultural connotation.

Bamboo and rattan furniture is born with a strong sense of history and culture atmosphere. It is made of natural and eco-friendly material with multiple technology and changeable style and will never die throughout the human furniture history. China, as a country of origin, should think about its models and cultural features first. Then, it should add the Chinese traditional patterns in the design to produce more unique products and create its own furniture brand.

\section{Types And Features of Chinese Traditional PATterns}

The traditional culture of China is broad and profound over the past 5000 years, including the uncountable classic patterns, designs and models. According to research, patterns appeared before written language, which reflected people's thoughts and emotion at that time such as pottery inscriptions and wall painting during the Stone Age. And Chinese traditional culture is always developing, such as glutton veins in Shang Dynasty, the phoenix design on the lacquerwork of Han Dynasty, the glyptography in Tang Dynasty and so on. Therefore, Chinese traditional patterns are extremely abundant. We divide those into four categories according to the source. Firstly, patterns from religion, such as legends, temples, wall paintings, statues, pedestals and buildings, which are rigorous and full of imagination. Secondly, patterns from folk handicraft products, such as embroideries, ceramics, window grilles, batik, paper-cut and sculpture, which are unvarnished and have a very strong local characteristics. Thirdly, they are patterns from Human calligraphy and poetry, such as fortune, prosperity and longevity. Fourthly, patterns from luxury, commodities, clothes and jewelry of feudal emperors, ministers, nobility and merchants, which are designed to satisfy the spiritual needs of users and made by professional craftsmen in special workshops. In general, the features of Chinese traditional patterns are: firstly, there is a central point on a Chinese traditional pattern, especially on the propitious pattern, which always has a central point or the structure with a central line. Secondly, Chinese traditional pattern seeks rhythm and rhyme, contrast and harmony, not the simple repeating but the unity of overall and change of part. Thirdly, the selected material of a Chinese traditional pattern is often from nature and the common animals in our daily life. It will abstract its image, which can reflect the beauty of abstract art.

\section{FeAtures of BAmboO AND RAtTAn Furniture PATtERnS}

Bamboo and rattan furniture is made of bamboos and rattans, whose fracture surfaces are circular or oval with the diameter from a few millimeters to several millimeters. Rattans are flexible and easy to blend, so bamboo and rattan furniture is mainly woven by bamboos and rattans, which also gives it artistic features of free and random, fine lines and full dynamic. In my opinion, its patterns are mainly divided into weaving decorative patterns and surface decoration patterns. There are three kinds of weaving decorative patterns: the surface layer weaving pattern, the structure decorative pattern and the art decorative pattern.

The surface layer weaving is the planar structure of bamboo and rattan furniture, which is supplied with a frame body by the materials like wood and metal and woven based on this frame body. The feature of the bamboo and rattan furniture on the rattan surface is the weaving pattern, which is easy to form a rattan surface. ii. The bamboos and rattans of the structure decorative pattern are flexible and easy to blend. In order to improve the stability and strength and enrich the styles of the furniture, in the frame body is added the structure decorative elements, such as handrail brackets, body brackets and so on. This kind of pattern has a simple style and strong stability which can secure the structure of furniture. iii. The art decorative pattern plays a decorative part on the spreading of rattans and the ending of weaving. It is mainly applied in the corner parts of furniture. It can add an artistic temperament to the furniture and enlarge its shape space. Art decorative patterns have many abundant and changeable forms.

\section{The Research of Applying Chinese Traditional PATTERNS IN THE DECORATION OF BAMBOO AND RATTAN FURNITURE}

Because of its material properties, most of the components of bamboo and rattan furniture are made by weaving. Large areas of whole weave are called patch weave and detailed decorative weave are called partial weave by the author. On the weaving patterns and designs of bamboo and rattan furniture, it is held by the author that Chinese traditional patterns could be taken as elements and blended into bamboo and rattan furniture according to the characteristics of bamboo and rattan furniture, in order to make bamboo and rattan furniture bear the characteristics of Chinese traditional culture.

On the patch weave of bamboo and rattan furniture, its techniques could be concluded into irregular weaving techniques and regular weaving techniques. (i) Irregular weaving techniques. It is mainly applied into crafts and small decorations and could be represented by intricate patterns, weaving irregularly with varied weaving technique. According to that character, traditional Chinese calligraphy and paintings could be shown on bamboo and rattan to make them reflect a sense of humanistic art. (ii) Regular weaving techniques. The so called regular weaving techniques refer to repeat certain weaving techniques regularly in the decoration of bamboo and rattan furniture according to some patterns and design. This kind of technique is relatively free and could be applied in bamboo and rattan furniture systematically with large areas and it is easy to master and efficient to produce bamboo rattan furniture. Patterns adopted by regular weaving techniques are mainly simple geometric patterns. It is held by the author that many traditional Chinese patterns, such as water waves, auspicious clouds, endless knot, square floral designs, window pane, etc., are not only simple but also with Chinese characteristics, which could be applied into bamboo and rattan furniture with detailed weaving techniques after being designed.

Detailed regular weaving techniques of bamboo and rattan furniture include: (i) Pricking and covering method, which refers to weave one strip of bamboo and rattan along a straight line to another one according to certain rules (pick one and cover one, pick one and cover two, etc.), such as going through one strip of bamboo and rattan when making some rattan surfaces and could also wave in the way of arc in the process 
of weaving. (ii) Winding and covering method, mainly applied at the interface and foot of bamboo and rattan furniture and could play the function of beautifying furniture frame and improving the stability, generally winds rattan rinds and slices on furniture. It's not only a kind of decoration, but also a unique characteristic of bamboo and rattan furniture. (iii) Weaving and engraving method, increasing a layer of under craft with bamboo and rattan after finishing weaving the surface of bamboo and rattan furniture, could enrich the surface modeling of bamboo and rattan furniture, increase layer feelings and make simple rattan surface varied. (iv) Auxiliary weaving method, which is a method doing finishing process to rattan surfaces to make their modeling accurate and perfect after finishing weaving.

Partial weaving techniques of bamboo and rattan furniture are mainly applied in the partial decoration of bamboo and rattan furniture to beautify the interface of bamboo and rattan furniture structures, strengthen the overall structure and increase the artistry of bamboo and rattan furniture and they are also the finishing touch of embodying the overall decoration style of bamboo and rattan furniture. For example, knot decoration, which is the most common partial weaving decoration. Knots have been in Chinese traditional culture for a long time, could be traced back to the history of keeping records by tying knots and gradually evolve into a form of art afterwards. Chine knot, the most representative of knot decorations symbolizing wishes for safeness and completeness, has become a fix symbol constantly appearing on partial weaving decorations of Chinese traditional bamboo and rattan furniture. Additionally, common structural and partial decorations on bamboo and rattan furniture, such as edge, edge flower, vertical link, circumferential decoration and bow-back brace, are obviously distinctive because of different styles. For example swirl crotch ornamentation is the most common in Baroco style, but copper cash ornamentation is common in China.

Weaving decorations of bamboo and rattan furniture are generally simple geometric patterns and interlacing dots, paying attention to highly ornamentality, scientific technology, solid structure and philosophical romance. However, there are a large number of patterns with simple modeling, diversified forms and exquisite structure in Chinese traditional patterns, which have a strong "Chinese flavor". For example, square floral design and reel long pattern, both of which could used contemporarily to form intricate all-age reel long pattern, double reel long pattern, better reel long pattern, endless knot and other patterns. Square floral design is actually oriented from Chinese architecture and clothing patterns, symbolizing good luck and happiness, which could be applied into weaving the surface layer of bamboo and rattan furniture together with endless knot to reduce intermediate clearance and make the whole more compact with good moral. It's a successful case of applying typical Chinese traditional patterns in bamboo and rattan furniture. Here's also combined reel long pattern, which is actually oriented from Chinese knot, symbolizing safeness and mutual communication. Applied in bamboo and rattan furniture, it shows attractive appearance with good moral and Chinese characteristics.

\section{The Research of ApPlying Chinese Traditional PATTERNS IN THE SURFACE DECORATION OF BAMBOO AND RATTAN FURNITURE}

Besides applied in the weaving decoration of bamboo and rattan furniture, Chinese traditional patterns could also be applied in the surface structure. Main decoration techniques are as follows: i. carving decoration, a traditional Chinese technique, could be applied in the exposed structure of bamboo and rattan furniture, divided into relief and circular engraving. There is a long history for bamboo carving art in China, oriented from the Six Dynasties and wide spread in Ming and Qing Dynasty. The technique could relatively directly embody traditional Chinese patterns, but it has a high requirement of bamboo and technology. ii. Turn-yellow technique, which is a technology of curving on the surface of inside bamboo after making the bamboo flat by baking and other procedures. It demands extremely highly for craftsmen and Chinese painting, character patterns and other Chinese elements could be used elaborately in the exquisite works beyond compare they made. iii. Pyrograph decoration technique, which irons out patterns on the surface of bamboo to decorate using high temperature before bamboo and rattan are carbonized. Pyrograph decoration technique could be directly used to draw patterns on bamboo and rattan furniture. iv. The decoration of pasting inside bamboo with glue, which is a very delicate technology boiling, drying and flattening the inside bamboo and then pasting on the surface of furniture and decorations. The best products are usually pasted with inside bamboo of above three layers and the decoration patterns usually used include square floral design, lotus, plalindrome and other characters. v. Painted decoration technique, which is a technique curving patterns on the surface of bamboo and rattan furniture, and then pain colors on the curved patterns.

The surface decoration techniques of bamboo and rattan furniture are varied with unique skills. Chinese traditional patterns could be applied extremely figuratively on the surface of bamboo and rattan furniture, embodying the humanistic connotation of bamboo and rattan furniture, giving bamboo and rattan furniture Chinese cultural characteristics, showing the unique understanding of Chinese people to bamboo and rattan such texture and their love to bamboo and rattan furniture and exploring the humanistic feelings of Chinese bamboo and rattan furniture.

\section{CONCLUSIONS}

With the current deterioration of the natural environment, low carbon, environmental protection and energy saving become the theme of the time and people advocate nature and returning to the nature increasingly. The design of furniture turns to the pursuit of natural, environmental protection, pay attention to regional culture and advocate the spirit of humanism. Under the background of the era, bamboo and rattan furniture is coming back to the front of us in a new attitude with its unique artistic charm. There's a long history for bamboo and rattan furniture in China and there are many classic bamboo and rattan furniture leaving immortal stamps in the furniture manufacturing history of human and still flashing until now. We should adhere to the unique traditional manufacturing technology of bamboo rattan furniture of China 
and apply current technical means to improve quantitative indicators and technical parameters of bamboo and rattan furniture manufacturing, absorb nutrients from the native culture of our country, apply abundant Chinese traditional patterns in the design of bamboo and rattan furniture, deal with the blank of bamboo and rattan furniture in modern value system with the rebound of traditional values, endow bamboo and rattan furniture a new life, embody the humanistic connotation of bamboo and rattan furniture and give bamboo and rattan furniture Chinese cultural characteristics. Making China's own bamboo and rattan furniture and creating a way full of Chinese traditional cultural connotations to make China's bamboo and rattan furniture create a separate school in the world.

\section{REFERENCES}

[1] Yuan Zhe. A Study of Rattan Furniture [D]. Nanjing Forestry University, 2006(6).

[2] Yan Danting. A study of the Decorative Arts and Combination Methods of Bamboo and Rattan Furniture [D]. Central South University of Forestry and Technology, 2007, (6).

[3] Zuo Chunli, Yue Jinfang. Simple Analysis of the Structure and Modeling of Bamboo and Rattan Furniture [J]. Guangxi Journal of Light Industry, 2011, (1)

[4] Zhou Yue. A Research of Designing Bamboo and Rattan Home Appliance - the Carrier of Style [D]. Zhejiang University of Technology, 2011, (5).

[5] Liu Xiaojian, Xu Zhanmin, Zhou Yue. The Development History and Secondary Innovation of Bamboo and Rattan Furniture [J]. Packaging Engineering, 2009 (30).

[6] Wang Shouzhi, History of World Contemporary Design [M]. China Youth Publishing House, 2002. 